\title{
Does organizational performance affect employee turnover? A re-examination of the turnover-performance relationship
}

\author{
Weijie Wang ${ }^{1}$ (1) I Rusi Sun ${ }^{2}$
}

${ }^{1}$ Truman School of Public Affairs, University of Missouri, Columbia, MO, USA

${ }^{2}$ Department of Social Sciences, University of Michigan-Dearborn, Dearborn, MI, USA

\section{Correspondence}

Weijie Wang, Truman School of Public Affairs, University of Missouri, 236 Middlebush Hall, Columbia, MO 65201, USA.

Email: wangweij@missouri.edu

\begin{abstract}
A common problem with using organizational performance as the dependent variable is the ignoring of feedback effects. The current conceptualization of the turnover-performance relationship is mostly unidirectional, focusing on how turnover affects organizational performance. Only a few scholars have investigated the possible reverse relationship between turnover and performance. Aiming to further the research on the feedback effect of organizational performance, this study employed cross-lagged structural equation models that are especially suitable for modelling the possible reverse relationships between variables. Data were collected from public elementary and middle schools in New York City over a three-year period. The results consistently show that organizational performance was negatively related to subsequent employee turnover. This research contributes to the development of a more valid and comprehensive understanding of the relationship between employee turnover and organizational performance.
\end{abstract}

\section{1 | INTRODUCTION}

The employee turnover-organizational performance relationship has been studied extensively in the general management literature. Several theoretical conceptualizations of this relationship have been developed, including an inverted-U-shaped relationship (Abelson and Baysinger 1984; Meier and Hicklin 2008; Siebert and Zubanov 2009), an attenuated negative relationship (Shaw et al. 2005; Ton and Huckman 2008), and a linear negative relationship (Shaw et al. 2005; Park and Shaw 2013; Hale et al. 2016). In the public management literature, research on the turnover-performance relationship has been growing but is still limited. Grissom et al. (2016) concluded in their 
review of turnover research in public administration that the dynamics of the relationship between turnover and performance remain uncertain' (p. 247). To name a few studies on the relationship, Meier and Hicklin (2008) studied teacher turnover in Texas public schools and supported the inverted-U model. Lee (2018) used data from US federal agencies and found an inverted-U relationship between employee transfer and perceived organizational performance and a linear positive relationship between involuntary turnover and perceived organizational performance. An (2019) found an inverted-U relationship between involuntary turnover and the performance of Florida school districts.

The current theorizing of the turnover-performance relationship is mostly unidirectional, focusing on how employee turnover affects organizational performance. The inverted-U-shaped model, attenuated negative model and linear negative model all treat organizational performance as the ultimate dependent variable with little consideration of the potential feedback of performance. However, producing outputs and outcomes is not the end of organizational processes but feed back to organizational decision-making. March and Sutton (1997) argue that a unidirectional account of how various variables affect organizational performance misses the rich feedback dynamics of organizational performance, and thus is likely to fail to fully account for the relationships. As the behavioural theory of the firm contends, managers constantly compare organizational performance with aspirational levels and make necessary adjustments if there is a performance shortfall (Cyert and March 1962; Greve 2003). For example, organizations may strengthen performance management, or cut slack resources or programmes that do not benefit performance immediately, leading to an increase in involuntary turnover. In the meantime, these measures may change the psychological contracts that employees have established with their organizations, or simply produce greater pressure on employees, leading to a decrease in organizational commitment and an increase in voluntary turnover. Recent research in public management has also started to investigate how organizational performance feeds back to affect managerial decision-making, risk taking or performance information use (Meier et al. 2015; Ma 2016; Holm 2017; Nicholson-Crotty et al. 2017).

Unfortunately, only a few scholars have investigated the possible reverse relationship between turnover and performance (Koys 2001; Glebbeek and Bax 2004; Meier and Hicklin 2008), and existing research has not sufficiently captured the complicated relationship between the two (Grissom et al. 2016). Therefore, we take further steps to examine whether a reversed relationship exists between employee turnover and organizational performance with a method that is especially suitable for this task.

We tested our hypotheses using data from public elementary and middle schools in New York City over a threeyear period. Cross-lagged structural equation models were used to model the reverse relationship between teacher turnover and school academic performance. With different measures of performance and employee turnover, we found consistently that organizational performance was negatively related to subsequent teacher turnover.

This study has made several contributions: First, the major contribution is the finding of a reverse relationship between employee turnover and organizational performance. We find a missing link and contribute to a more comprehensive understanding of the turnover-organizational performance relationship in public organizations. The finding has important research and managerial implications, which are discussed in detail later. Moreover, our results support March and Sutton's (1997) view that the feedback effect of organizational performance should not be ignored in organization studies. We expand the burgeoning public management literature that has investigated the feedback effect of organizational performance (Meier et al. 2015; Holm 2017; Nicholson-Crotty et al. 2017; Hong 2019). Specifically, we examine performance feedback on employee turnover, which has not yet attracted much attention.

\section{2 | LITERATURE REVIEW}

\subsection{The impact of employee turnover on organizational performance}

Several theoretical perspectives have been developed regarding the relationship between employee turnover and organizational performance. Cost-benefit theories suggest that the relationship has an inverted-U shape. The idea is that turnover is not always dysfunctional. At a low to moderate level, the benefits outweigh the costs because poor 
performers are dismissed and newcomers bring in new skills and knowledge. However, when turnover reaches a certain point, the disruption may outweigh the above-mentioned benefits (Abelson and Baysinger 1984). This invertedU-shaped relationship is supported by a number of studies (Meier and Hicklin 2008; Siebert and Zubanov 2009).

Some scholars have proposed an attenuated negative relationship between employee turnover and organizational performance. From this perspective, when employee turnover is low, employees' average firm-specific human capital is high, and thus it takes a considerable amount of time for new hires to reach the average level of human capital. In contrast, when employee turnover is high and many employees are short tenured, the average firm-specific human capital is low, and thus it will not take much time for new hires to reach the average level. A number of studies have shown that the negative effect attenuates as the level of turnover increases (Shaw et al. 2005; Ton and Huckman 2008).

The conventional view holds that employee turnover negatively affects organizational performance (Morrow and McElroy 2007; Park and Shaw 2013; Hale et al. 2016). In addition to creating direct costs, such as replacement costs and new-hire training costs, employee turnover may have even more significant indirect costs. From the perspective of human capital theory, the departure of experienced employees leads to a loss of firm-specific knowledge and skills because the replacements need time to develop the same levels of knowledge and skills (Strober 1990). As a result, organizational performance may suffer in the short term. Social capital theory suggests that employee turnover damages knowledge sharing, group transactive memory and trust, and thus has exponential negative effects on organizational performance (Leana and Buren 1999; Dess and Shaw 2001).

More nuanced views of the linear negative relationship have been developed. Scholars have explored variables that may moderate this relationship. Siebert and Zubanov (2009) found that different types of work systems moderate how turnover affects performance. Specifically, in a commitment work system that features careful selection in recruitment and non-routinized work, there will be a linear negative relationship. Meier and Hicklin (2008) suggested that task difficulty is a moderating variable and found that when the level of task difficulty was low, the relationship between employee turnover and organizational performance was linear and negative. Other moderating variables include industry, location and firm size (Hancock et al. 2013; Park and Shaw 2013).

Another development in the literature to sort out the turnover-performance relationship is to distinguish the effects of voluntary and involuntary turnover. Unfortunately, the current literature offers inclusive and inconsistent findings. Despite some findings that the impacts of voluntary and involuntary turnover on organizational performance are quite similar (Batt and Colvin 2011; Hancock et al. 2013), robust evidence has suggested otherwise (Park and Shaw 2013). For example, involuntary turnover has been found to have a positive relationship with organizational performance because employees with performance deficiencies or behavioural problems are dismissed and replaced (Holtom et al. 2008; Lee 2018), yet An (2019) found an inverted-U-shaped relationship between the two, suggesting that a higher level of involuntary turnover is harmful. Both An (2019) and Lee (2018) failed to find a statistically significant relationship between voluntary turnover and organizational performance, while Moon (2017) found an inverted-U relationship between the two with data from US federal agencies. The inconsistent findings suggest that organizational contexts may play a moderating role, and better measurement of key variables, such as organizational performance, and more rigorous statistical models may be needed to further the research.

In the economics of education literature, the linear negative relationship has received considerable empirical support (Ronfeldt et al. 2013). A meta-analysis suggests that high-achieving teachers are more likely to leave compared with their less talented counterparts (Borman and Dowling 2008), although some research found more complicated patterns that ineffective teachers are more likely to leave in public schools or high-quality and low-quality teachers leave at a higher rate than do average-quality teachers (Hanushek et al. 2005; Goldhaber et al. 2011; Feng and Sass 2017). These departing teachers are likely to be replaced by beginning teachers, who are substantially less effective than experienced teachers (Rivkin et al. 2005). School performance may be negatively affected, at least in the short term, by the increase in inexperienced teachers. On the other hand, even if departing teachers and their replacements have equal levels of effectiveness, teacher turnover may still exert a disruptive effect on the remaining teachers and students (Ronfeldt et al. 2013). The quality of relationships and trust between teachers and between teachers and students have been shown to be positively related to student achievement (Bryk and Schneider 2002). 
A high level of teacher turnover harms the level of trust and the quality of relationships, thus negatively affecting student achievement.

The current literature does not provide a conclusive prediction of the employee turnover-organizational performance relationship, but it seems to suggest that organizational context plays an important moderating role. Since our study is based on the education context, and the economics of education literature seems to favour the linear negative relationship, we propose that:

Hypothesis 1: Public school teacher turnover is negatively associated with subsequent school academic performance.

\section{2 | The impact of organizational performance on employee turnover}

Most literature considers organizational performance as a consequence of employee turnover, and the possible reverse effect of organizational performance on turnover has received limited attention. To the best of our knowledge, only a few studies have tested this reverse relationship and have not found evidence to support it (Glebbeek and Bax 2004; Meier and Hicklin 2008). Koys (2001) treated this reversed causation as the major research focus, and he did not find a statistically significant effect either. However, his study was limited by a small sample size ( $N=28$ over a two-year period).

Based on the behavioural theory of the firm and other organization theories, we have good reasons to suspect that the turnover-performance association is more complicated than the unidirectional relationship that has dominated the current literature. The behavioural theory of the firm first brought the feedback effect of organizational performance to scholars' attention (Cyert and March 1962). March and Sutton (1997, p. 701) pointed out that 'the effects of performance on organizational predictor variables are frequently forgotten in research that purports to identify factors in organizational performance'. Because the feedback effect of organizational performance operates through multiple mechanisms, a simple unidirectional interpretation of performance may not be valid (March and Sutton 1997). More recent literature on organizational learning from performance feedback further developed this perspective (Greve 2003). Organizations monitor performance, and when performance falls short of past performance or peer performance, they will identify alternatives to their current activities to mend performance (lyer and Miller 2008). Under the pressure of performance shortfalls, organizations may take a variety of measures, such as risk taking (Audia and Greve 2006), adoption of innovations (Salge 2011) or even illegal action (Desai 2014).

Public management scholars have noted the lack of research on the feedback effect of organizational performance (Meier et al. 2015; Nicholson-Crotty et al. 2017). Meier et al. (2015) developed theoretical propositions on how performance gaps motivate managers to make decisions such as risk taking and information seeking. Empirical research has supported the feedback effect by showing that organizational performance in relation to aspiration levels affects further performance improvement (Hong 2019), budgetary changes (Flink 2019) and innovation in organizations (Nicholson-Crotty et al. 2017). Despite the increasing attention given to performance feedback, a question remains to be addressed: given the performance feedback that public management scholars have identified, does organizational performance affect subsequent employee turnover?

Organizational responses to performance shortfalls may increase both voluntary and involuntary turnover. One natural organizational response is to strengthen performance evaluation and management. Low-performing employees are more likely to be punished or even fired. Poor performance also triggers restructuring and downsizing in order to increase efficiency. Programmes that do not contribute to performance directly or immediately are cut, resulting in an increase in involuntary turnover. Moreover, organizational responses may increase voluntary turnover through multiple mechanisms. First, the new measures may produce greater pressure and psychological discomfort on employees, and thus lower their morale and commitment to the organization, which leads to employee voluntary turnover. Second, employees are more likely to feel a breach in psychological contracts. Under stable conditions, organizations may hoard resources or personnel to buffer themselves from environmental and internal fluctuations, 
and the resources and personnel may have to be cut in tough times (Sharfman et al. 1988; Tan and Peng 2003; Love and Nohria 2005). As a result of slack reduction, organizations may not be able to fulfil some of their promises such as pay rises, benefits or professional development opportunities. If perceived promises are not kept and expectations are not met, employees may feel a breach in their psychological contracts (Aselage and Eisenberger 2003). They may thus reciprocate by decreasing their commitment to organizations (Zhao et al. 2007; Bal et al. 2008). Studies have shown that in organizations that are undergoing restructuring, employees are more likely to feel the violation of their psychological contracts and respond by resigning (Robinson and Rousseau 1994; Turnley and Feldman 1999).

Organizational performance shortfall may have especially powerful effects on new employees because this is a strong negative signal in their sense-making processes. New employees typically have limited information about their organizations. They actively seek information to make sense of their new environment (Morrison 1993; De Vos et al. 2003). The organizational socialization literature conceptualizes this stage as the 'encounter stage', which is believed to shape individuals' long-term commitment towards their organization (Louis 1980). Poor organizational performance and subsequent responses to improve performance, such as cutting slack resources, could send troublesome signals to new employees. For example, they may worry about their future job security and whether what has been promised to them in the recruitment stage will be fulfilled. Because they may not have the 'local interpretation schemes' and 'others' interpretations' to adequately make sense of their new environments (Louis 1980), for example, to understand whether poor performance is systematic or temporary, they are likely to pick up the signal and misinterpret it. As a result, uncertainty may shadow the formation of psychological contracts with their organization, which may lead employees to doubt their fit with their organization. Employees may adjust themselves by lowering their level of commitment to their organization, and thus are more likely to leave (De Vos et al. 2003). Since there has been a dearth of empirical analysis of the potential impact of organizational performance on employee turnover, we propose that:

Hypothesis 2: Public schools' academic performance is negatively associated with subsequent teacher turnover.

\section{3 | METHODS}

\section{1 | Data}

We used data on public schools in New York City to test our hypotheses. The New York City Department of Education (NYCDOE) manages the largest school district in the country, serving 1.1 million students. The operating budget of the NYCDOE in the 2016-17 school year was about \$23.1 billion (New York City Department of Education 2016). Regular public schools in NYC operate within the same institutional environment with the same statemandated learning standards and personnel policies (e.g., tenure policy).

We compiled data on school academic performance, teacher turnover rate, student demographics, and teacher and school characteristics. The dataset included about 1,065 public elementary and middle schools that participated in the standardized English Language Arts and Mathematics tests from the 2009-10 school year to the 2011-12 school year. Since these were state-wide standardized tests for Grades 3-8 in regular public schools, we excluded high schools, kindergarten, charter schools and special education schools. Elementary and middle schools that had missing data on independent or dependent variables were also dropped, including 46 new schools that did not have test results in all three years.

Our final dataset included 970 schools over the three-year period. The dataset covered a short period because of statewide changes made to the grading standards in the 2009-10 school year and the change of learning standards to the Common Core State Standards after 2012, which rendered the school performance data incomparable. For example, the cut-off points of the proficiency standards were raised in the 2009-10 school year, which reduced the percentages of students meeting proficiency standards. In addition, the cut-off scores were raised differently across grades, meaning that the adjustment of cut-off scores had different impacts on schools depending on the 
composition of grades in the first place. Research that used data from NYC public schools took the same approach of not combining data before and after the 2009-10 school year (Zambrano-Gutiérrez et al. 2017). We checked the technical reports of each year of the study period to ensure that the cut-off points were consistent.

\section{2 | Measurement}

We used the proportion of students in a school that had met or exceeded the proficiency standards (Level 3 or 4) in the statewide English Language Arts and Mathematics tests as the two measures of school performance. Since academic performance is one of the key outcomes of public schools, student performance in standardized tests is the most commonly used measure of school performance in public management research (Meier and O'Toole 2002; Meier and Hicklin 2008; Hvidman and Andersen 2014; Nielsen 2014). In practice, the No Child Left Behind Act requires that all states use the annual testing of students to measure the 'adequate yearly progress' of schools (No Child Left Behind [NCLB] 2001). Proficiency rates were also the main accountability tool that the New York State Education Department and New York City Department of Education used during the period of the study. Because the data on student performance in standardized tests are widely available and recognized as important indicators of school achievement by educators, policy-makers and the public, we used student proficiency rates as the measure of school performance.

Nonetheless, scholars have long been aware of the limitations of using only student performance in standardized tests to measure school performance. For example, student performance in tests only captures academic achievement and does not take other measures, such as drop-out rates and transfer rates, into account (Rumberger and Palardy 2005). Moreover, education is more than academic achievement, and test results fail to capture other aspects of education. In particular, the proficiency rates that we used have some limitations. First, proficiency rates are not a good measure of student progress. Some students may be making strides from Level 1 to Level 2 , but because they still fall short of the cut-off points, they would be considered as not meeting proficiency standards. Second, the same proficiency rates were used to measure the performance of all schools and thus the initial differences in student background were not taken into account. Disadvantaged schools may thus always fall behind more advantaged schools.

Teacher turnover data were obtained from the annual School Report Card published by the NYSED. We used two types of turnover rates: the overall turnover rate and the turnover rate of teachers with less than five years' experience. The overall turnover rate is the total number of teachers who did not teach in the following school year divided by the total number of teachers in the specified school year, and the turnover rate for beginning teachers is the number of teachers with fewer than five years of experience who did not teach in the following school year divided by the total number of teachers with fewer than five years of experience in the specified school year, expressed as a percentage. NYSED did not distinguish voluntary and involuntary turnover, so each reported measure was a combination of the two types of turnover.

We used the turnover rate of beginning teachers in the main regressions and overall turnover rates in the robustness checks. The major reason is that overall turnover included some forms of separation, such as retirement, that may not be strongly related to organizational performance. The relationship between organizational performance and subsequent overall turnover may be weaker. In contrast, the turnover of beginning teachers may be more responsive to organizational performance. Retirement typically was not a cause of turnover for beginning teachers. Although beginning teachers could be dismissed due to denied tenure or poor performance, evidence suggests that the percentages of these types of dismissal were very small. Loeb et al. (2015) found that among all of the teachers who applied for tenure after a three-year probationary period, the denial rate was about 2 to 3 per cent. The turnover rate caused by denied tenure among teachers with fewer than five years of experience is thus even lower due to a much larger denominator.

Student performance and teacher turnover are affected by students' demographics, school and teacher characteristics. Therefore, we controlled these variables in each wave. The control variables included: the percentages of female students, students who were English language learners, students who were eligible for free or reduced-price lunches, teachers who had fewer than three years of experience, and teachers with a master's degree or above. 
We included the percentages of students who were Asian, black, Hispanic or other races in the analyses. The percentage of white students was used as the reference category. In addition, school enrolment and pupil-teacher ratio were used as control variables.

\section{3 | Modelling strategy}

To investigate whether there is a reverse relationship between employee turnover and organizational performance, we used three-wave cross-lagged structural equation models. Cross-lagged structural equation models use the structural equation modelling framework and the time ordered nature of panel data to explore the temporal orderings of variables, and thus are particularly suitable for investigating whether there is a reverse relationship between variables (Finkel 1995). In cross-lagged structural equation models, the key variables are regressed on their own lagged scores and the lagged scores of other variables. The cross-lagged coefficients thus tell us 'how much variation in one variable at time $t_{1}$ is able to predict change in the other variable between times $t_{1}$ and $t_{2}$, net of any controls specified in the model' (Berrington et al. 2006, p. 23). The inclusion of lagged dependent variables helps to control for the effects of some unobserved confounding variables, although it cannot completely remove the unobserved unit heterogeneity (Allison 1990; Glymour et al. 2005). We allowed the disturbances (residual variances of endogenous variables that could not be explained by the model) within the waves to covary. For the sake of simplicity, the covariance between the disturbances and control variables is not shown in the following figures.

We used Stata 14 to test the model in Figure 1. The cross-lagged associations and autoregressive associations between variables from one wave to the next were assumed to be equal, as is often done in fixed or random effects models and in cross-lagged models when the periods between waves are equal (Finkel 1995; Berrington et al. 2006). The assumption was that the cross-lagged and autoregressive associations were stable across years, which improved model parsimony. We also ran a model that relaxed the assumption of constant effect as a robustness test.

\section{\begin{tabular}{l|l}
4 & RESULTS
\end{tabular}}

\section{1 | Descriptive statistics}

Table 1 shows the descriptive statistics of and correlation coefficients between key variables. The percentages of students who reached and exceeded the proficiency standards in ELA and Mathematics tests ranged from 42.9 per cent to 46.8 per cent, and 54.2 per cent to 59.1 per cent, respectively, which suggests that student performance during the study period was generally stable with a slight upward trend. The average turnover rates of beginning teachers were between 17.5 per cent and 19 per cent, while the highest turnover rate of any school during this three-year period was 89 per cent. The turnover rates of beginning teachers were a little higher than the overall teacher turnover rates of these schools over the same period (14.0-14.8 per cent), suggesting that beginning teachers were more likely to leave. The annual teacher turnover rates in NYC were close to the rates throughout the country. In the 2012-13 school year, the national average percentage of teachers who left their schools or the profession was 15.8 per cent, while the turnover rate for teachers with fewer than three years of experience was 19.6 per cent (Goldring et al. 2014).

Descriptive statistics of control variables are presented in Table A1 in the appendix. To briefly summarize here, in 2010, on average about 9.3 per cent of teachers had less than three years' experience, and about 40.78 per cent of teachers had a master's degree or above. Moreover, 14.5 per cent of students were English language learners; 85.6 per cent of students were eligible for free or reduced-price lunch, which suggests that most students were from low-income families; and 50.7 per cent of students were male. Hispanic students were the largest ethnic group, constituting about 40 per cent of the student body, whereas black and white students constituted about 31.6 per cent and 14.5 per cent of the student body, respectively. 


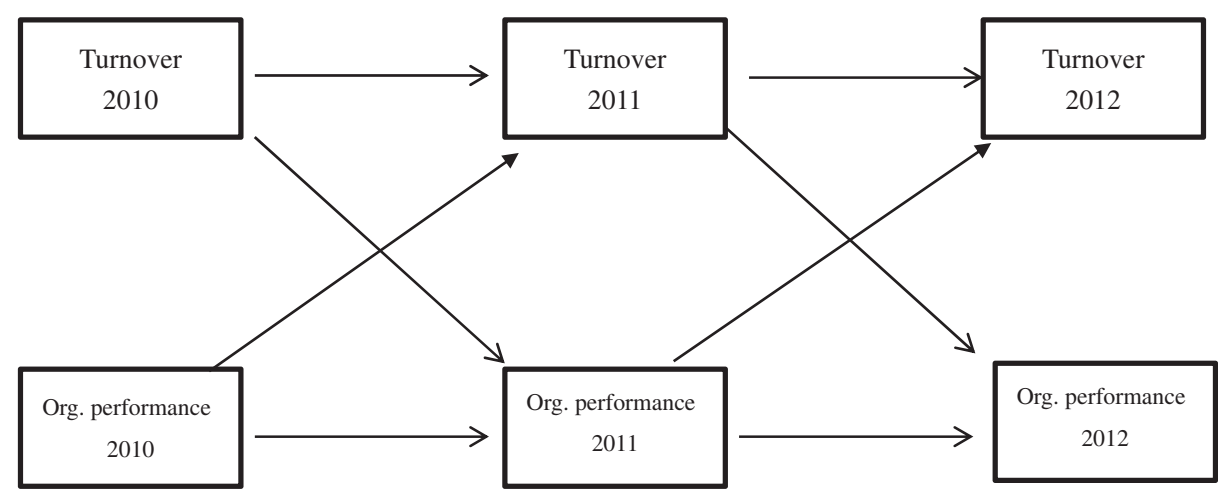

FIGURE 1 Theoretical model

Note: Control variables are not shown in the model for clarity and brevity

Correlation coefficients between key variables suggested that school academic performance of the same school was highly correlated over the years. For example, the correlation coefficients between student performance in ELA exams across three years ranged from 0.95 to 0.97 , suggesting that school performance was highly stable over the study period. The turnover rates of beginning teachers were not strongly correlated over the three years, ranging from 0.12 to 0.21 . Teacher turnover rate had negative but weak association with school academic performance, with all the coefficients below or near -0.3 .

\section{2 | Cross-lagged structural equation models}

Following the recommendations of several studies (Hu and Bentler 1999; Schermelleh-Engel et al. 2003), we used the following fit statistics to check model fit: (1) a ratio of $\chi^{2}$ to degree of freedom ( $\chi^{2} / d f$ ) of 5 or less; (2) a standardized root mean square residual (SRMR) of 0.05 or less; (3) root mean square error of approximation (RMSEA) of 0.05 or less; and (4) a comparative fit index (CFI) value of 0.95 or above.

Figures 2 and 3 report the results of cross-lagged SEM models that test the reverse relationship between turnover rates of teachers with less than five years' experience and school performance, measured by student proficiency rates in ELA and mathematics exams, respectively. Both ELA $\left(\chi^{2} / d f=3.67 ;\right.$ SRMR $=0.012$; RMSEA $=0.052$; $\mathrm{CFI}=0.95)$ and mathematics models $\left(\chi^{2} / d f=3.27\right.$; SRMR $=0.012$; RMSEA $\left.=0.048 ; \mathrm{CFI}=0.95\right)$ fit the data well. In both models, the autoregressive effect of organizational performance was very strong, as indicated by the coefficients of 0.90 and 0.86 , which means that high-performing schools in a certain year were very likely to perform well in the following year. In the ELA model, the association between beginning teacher turnover and subsequent students' performance in ELA exams was negative and statistically significant, adjusting for the prior level of performance and control variables. Hypothesis 1 was thus supported by this model, although the effect size was small-the standardized regression coefficient was only -0.01 and the unstandardized coefficient was -0.02 . Consistent with hypothesis 2 , we found a negative and statistically significant relationship between school performance and subsequent turnover of beginning teachers, adjusting for the prior level of employee turnover and control variables. The unstandardized coefficient was -0.14 .

In the mathematics model, we also found a negative and statistically significant relationship between school performance and subsequent beginning teacher turnover, adjusting for the prior level of employee turnover and control variables. Hypothesis 2 was thus supported again by this model. The unstandardized coefficient was -0.14 . However, the leaving of beginning teachers did not have a significant impact on students' performance in subsequent mathematics exams. The current literature often found that variables affecting student performance in mathematics 


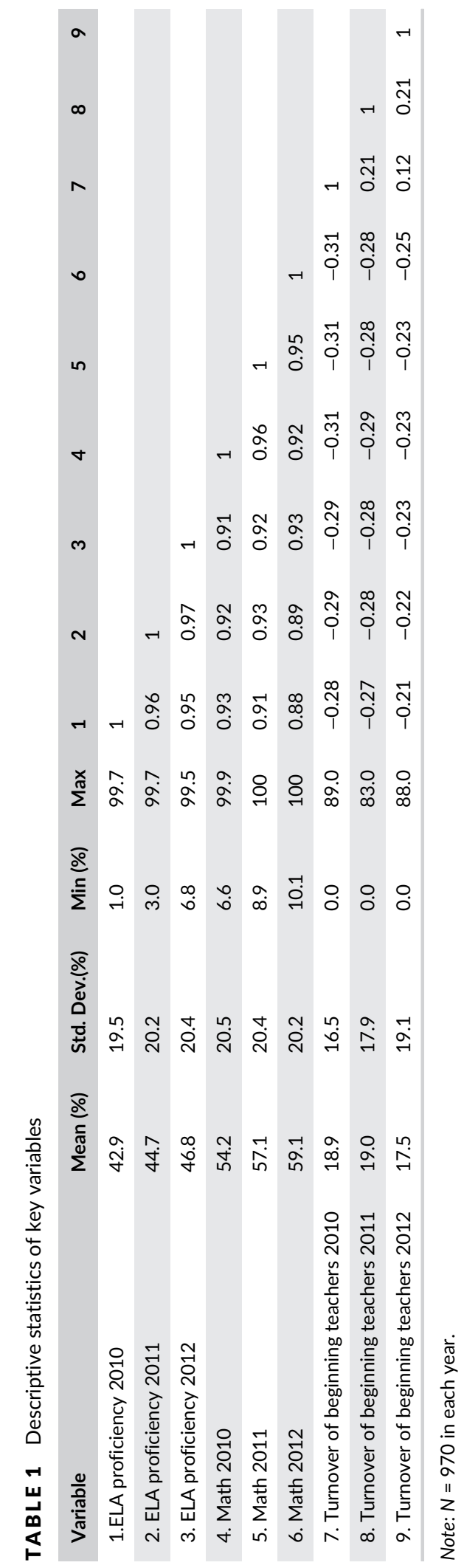




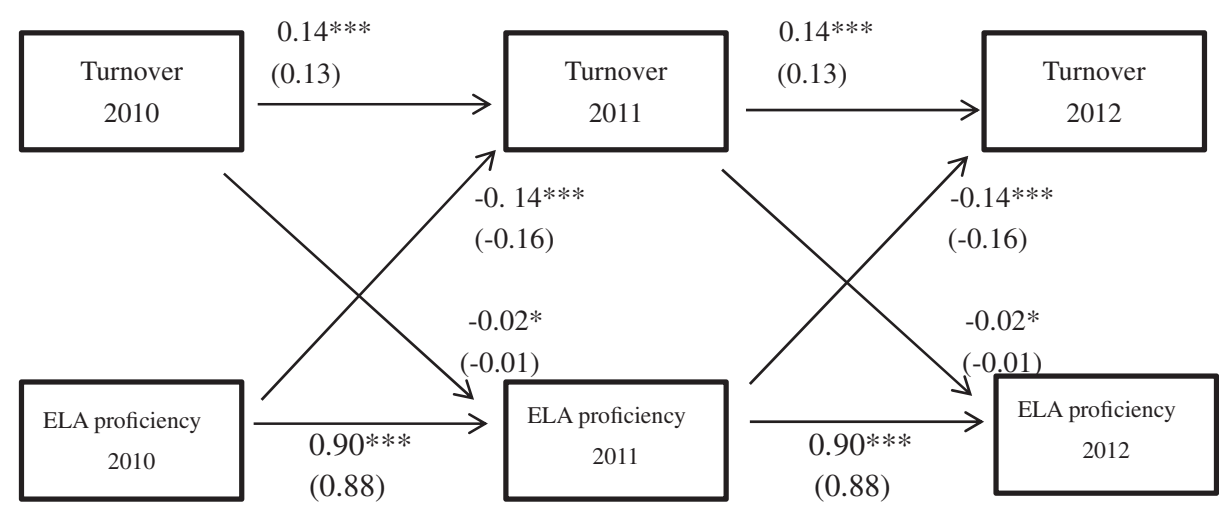

FIGURE 2 ELA proficiency as the dependent variable

Note: Standardized coefficients in parentheses; covariates were controlled in each wave; cross-lagged and autoregressive effects were constrained to be equal;** $p<.05 ; * * * p<.01$

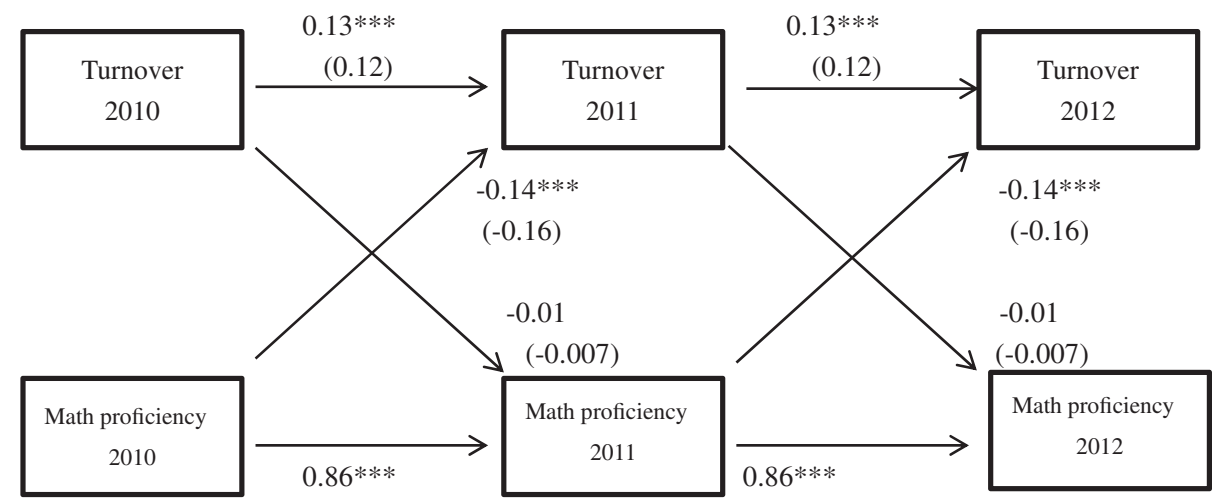

$(0.87)$

$(0.87)$

FIGURE 3 Mathematics proficiency as the dependent variable Note: Standardized coefficients in parentheses; covariates were controlled in each wave; cross-lagged and autoregressive effects were constrained to be equal; ** $p<.05 ; * * * p<.01$

and ELA tests are different or have different magnitudes (Jepsen 2005; Dobbie and Fryer 2013). We thus found another factor that had different impacts on mathematics and ELA test results. Improving students' mathematics skills may have more to do with factors such as pedagogy or school resources.

In sum, we found evidence that the association between school performance and subsequent turnover of beginning teachers was negative and statistically significant. However, the negative association between the turnover of beginning teachers and students' performance in subsequent standardized exams was only partially supported.

\subsection{Robustness checks}

We conducted a series of robustness checks to test the robustness of our findings. First, we re-conducted all the analyses with the quasi-maximum likelihood method that relaxes the conditional normality assumptions and handles nonnormality better. Results, which are shown in Figures A1 and A2 in the appendix, are basically the same as the results with the maximum likelihood method. 
We relaxed the assumption that autoregressive and cross-lagged associations between waves were equal. Figure 4 shows this model with ELA proficiency as the measure of performance. The overall fit of this model was comparable to that of the ELA model in Figure 2. The $\chi^{2}$ was 517.62 and the degree of freedom was 139 , resulting in a ratio of 3.71. The ratio was well below the cut-off point of 5. The SRMR was 0.012, and the CFI was 0.95 . The RMSEA was 0.053, which was slightly bigger than the cut-off point. The reverse relationships from organizational performance to subsequent employee turnover were both negative and statistically significant, so hypothesis 2 was supported by this model again. However, the link between employee turnover in 2011 and organizational performance in 2012 was not statistically significant. It provided partial support to hypothesis 1.

To check whether the findings were robust to a different measure of turnover, we used the overall teacher turnover rates in the cross-lagged SEM models. The results are presented in Figure 5. The fit indices suggested an acceptable model fit $\left(\chi^{2} / d f=4.58 ;\right.$ SRMR $=0.014$; RMSEA $\left.=0.061 ; \mathrm{CFI}=0.93\right)$. Again, the association between school performance and ensuing overall employee turnover was negative and statistically significant, adjusting for the prior level of employee turnover and control variables. The unstandardized coefficient was -0.07 , which was much smaller than the coefficients in models with the turnover of beginning teachers. Overall turnover included some types of turnover, such as dismissal, that were not sensitive to organizational performance. However, the paths

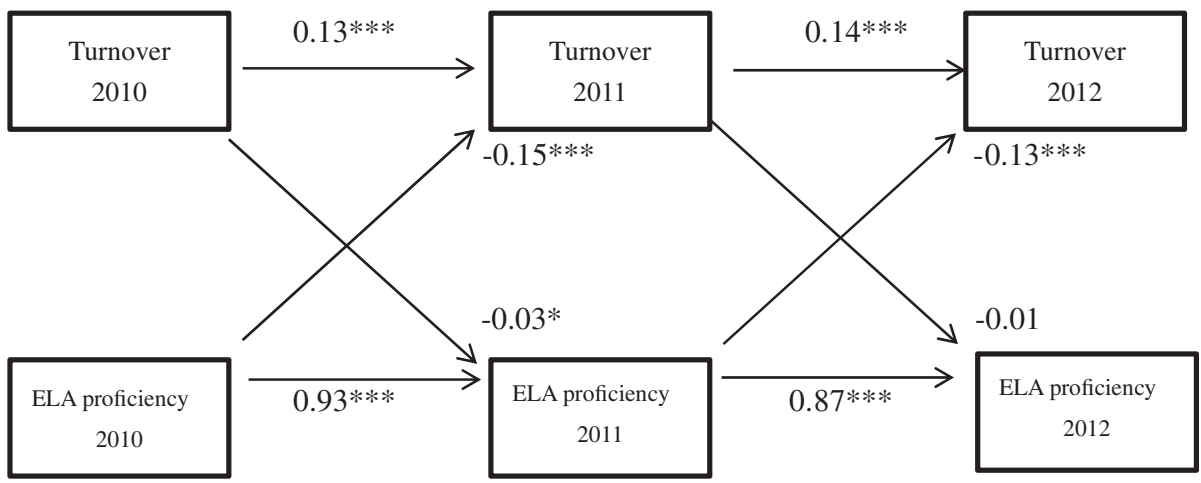

FIGURE 4 Model without constant autoregressive and cross-lagged association Note: Covariates were controlled in each wave; $* * p<.05 ; * * * p<.01$

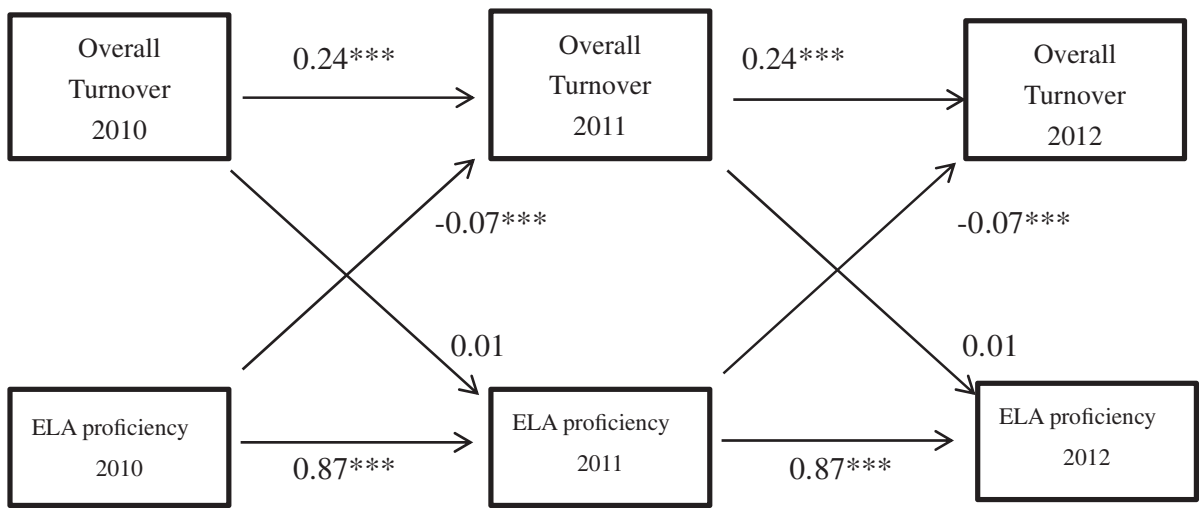

FIGURE 5 Overall turnover and ELA proficiency Note: Cross-lagged and autoregressive effects were constrained to be equal; covariates were controlled in each wave; ** $p<.05$; *** $p<.01$ 
between overall teacher turnover and school academic performance in the following years were not statistically significant after adjusting for the effect of prior levels of organizational performance and control variables. This may be caused by the strong correlation of school performance measured by students' ELA proficiency level over the years.

\section{5 | DISCUSSION AND IMPLICATIONS}

We employed three-wave cross-lagged structural equation models to examine the dynamic relationships between employee turnover and organizational performance. Using longitudinal data on public elementary and middle schools in New York City and multiple measures of school performance and teacher turnover rate, we found partial support for the linear negative relationship between employee turnover and subsequent school performance. The turnover of beginning teachers damages the social fabric that has been established and causes the loss of social capital, which negatively affects student learning (Moolenaar et al. 2012). Replacements are unlikely to rebuild the social capital in these schools within a short period of time. Therefore, we are likely to observe a negative association between turnover and subsequent school performance in the short term. Although we did not offer a direct test of the social capital mechanism through which employee turnover affects organizational performance, we believe that this is a good topic for future research.

We consistently found that the association between school performance and subsequent teacher turnover was negative and statistically significant, suggesting that organizational performance feeds back to organizations. Poor performance is associated with subsequent teacher turnover, and the association is stronger in the case of beginning teachers. This is not consistent with some previous research that found that organizational performance has no effect on employee turnover (Koys 2001; Meier and Hicklin 2008; Park and Shaw 2013). For managers, performance information is an important part of learning (Greve 2003). Performance shortfalls relative to past performance or peer performance affect decision-making and motivate managers to take various measures to address the problem (Meier et al. 2015). Organizations can respond by cutting resource slack, redistributing resources to more promising programmes, cutting low-performing programmes, or strengthening performance management. These measures may directly increase involuntary turnover, and affect employees' psychological contracts with organizations, leading to burnout, lower commitment and high voluntary turnover. Organizational responses to poor performance may be particularly problematic for new employees. For example, schools may respond to poor performance by threatening to deny tenure or extend the probationary period. Beginning teachers may thus be under more pressure and be more likely to burn out. This may change their original perceptions of their fit with schools and the teaching profession as a whole, and thus they may choose to leave their current schools. In turn, teacher turnover may be negatively associated with subsequent organizational performance due to the loss of organization-specific human capital and social capital. Figure 6 presents a dynamic model of the relationships between organizational performance and employee turnover.

An important implication for future research is that the reverse relationship between employees' turnover and organizational performance needs to be considered. Existing turnover research seldom considers past organizational performance as a factor related to employee turnover. This research finds the missing link and helps to build a more comprehensive understanding of factors related to employee turnover.

Moreover, this article contributes to the burgeoning literature on performance feedback in public management by expanding the focus to employee turnover. With the rise of the New Public Management movement, organizational performance is probably one of the most studied dependent variables in public management research. Scholars have studied the impacts of a wide range of variables, such as internal management and employee motivation, on organizational performance. However, the feedback effect of performance has only attracted some recent attention; scholars have studied performance feedback on variables such as budget changes, performance information use and goal setting (Nielsen 2014; Meier et al. 2015; Ma 2016; Nicholson-Crotty et al. 2017; Flink 2019). We expand the research by studying performance feedback on employee turnover. Nevertheless, the potential feedback effects of performance on other important variables, such as group sense-making, organizational social environment, and 


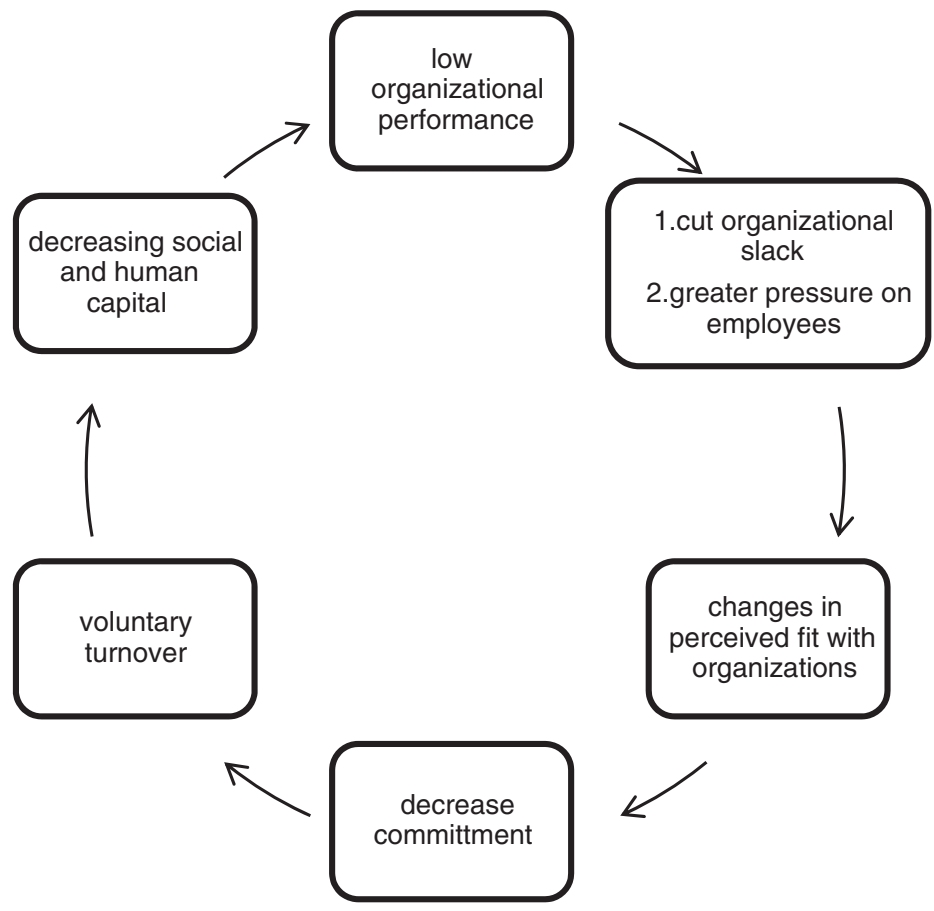

FIGURE 6 The dynamic relationship between organizational performance and employee turnover

employee attitudes and behaviour, are still left unexamined. Therefore, in public management research, more research is needed to elaborate and theorize the feedback effect on different variables and empirically test the relationships in different contexts. An implication for statistical modelling is that more consideration is needed on the reverse relationship in order to address endogeneity.

The research also carries important managerial implications for both improving performance and managing employee turnover. As Figure 6 shows, low-performing organizations run the risk of a vicious cycle: poor performance leads to a higher level of employee turnover, which further aggravates performance problems. For managers of struggling organizations, they should be aware of the negative consequences including losing valuable human capital; and to turn their organizations around, managing employee turnover strategically and maintaining important human capital is a key.

Our results should be interpreted in light of some limitations, especially some of the alternative explanations that this observational study cannot rule out. For example, the NYCDOE implemented a series of innovative reforms after 2002, which coincided with the time period of this study. Notably, teachers' impacts on student learning gains began to be taken into account in tenure decisions, thus departing from the previous situation in which 'the receipt of tenure had become an expectation for nearly all teachers' (Loeb et al. 2015, p. 200). We do not know how these reforms affected teachers' turnover intentions and behaviour, and it is likely that the reforms drove some teachers to leave voluntarily. If this was the case, then we could see an increase in teacher turnover. However, data do not seem to support this. We checked the annual turnover rates of teachers with less than five years' experience over the longer period from the 2007-08 school year to the 2011-12 school year. We observed that the turnover rates for this group of teachers were relatively stable and actually showed a slightly downward trend from 20.56 per cent in the 2007-08 school year to 17.4 per cent in the 2011-12 school year. Moreover, cross-lagged structural equation models are not a method of causal inference, which means that we are not telling a causal story here. Our findings should not be interpreted as causal relationships. What we found are associations between employee turnover and organizational performance at different time points. 
The last limitation is that we could not test the mechanisms through which organizational performance affects subsequent employee voluntary turnover due to data limitations and the contingencies that may moderate the performance-turnover linkage. Our discussions on the mechanisms, such as broken psychological contract in organizational socialization, are theoretical in nature. To test these mechanisms, we will need to do large-scale surveys of teachers to measure reality shocks or psychological contracts and then treat them as mediating variables. Testing these mechanisms in future research can keep furthering our understanding of the turnover-organizational performance relationship. This being said, we believe our study is an important first step in bringing attention to the feedback effect of performance on organizational variables.

\section{ORCID}

Weijie Wang (D) https://orcid.org/0000-0001-6997-5752

\section{REFERENCES}

Abelson, M. A., \& Baysinger, B. D. (1984). Optimal and dysfunctional turnover: Toward an organizational level model. Academy of Management Review, 9, 331-341.

Allison, P. D. (1990). Change scores as dependent variables in regression analysis. Sociological Methodology, 20, 93-114.

An, S.-H. (2019). Employee voluntary and involuntary turnover and organizational performance: Revisiting the hypothesis from classical public administration. International Public Management Journal, 22, 444-469.

Aselage, J., \& Eisenberger, R. (2003). Perceived organizational support and psychological contracts: A theoretical integration. Journal of Organizational Behavior, 24, 491-509.

Audia, P. G., \& Greve, H. R. (2006). Less likely to fail: Low performance, firm size, and factory expansion in the shipbuilding industry. Management Science, 52, 83-94.

Bal, P. M., De Lange, A. H., Jansen, P. G. W., \& Van Der Velde, M. E. G. (2008). Psychological contract breach and job attitudes: A meta-analysis of age as a moderator. Journal of Vocational Behavior, 72, 143-158.

Batt, R., \& Colvin, A. J. S. (2011). An employment systems approach to turnover: Human resources practices, quits, dismissals, and performance. Academy of Management Journal, 54, 695-717.

Berrington, A., Smith, P., \& Sturgis, P. (2006). An overview of methods for the analysis of panel data. Southampton: ESRC National Centre for Research Methods Briefing Paper.

Borman, G. D., \& Dowling, N. M. (2008). Teacher attrition and retention: A meta-analytic and narrative review of the research. Review of Educational Research, 78, 367-409.

Bryk, A., \& Schneider, B. (2002). Trust in schools: A core resource for improvement. New York: Russell Sage Foundation.

Cyert, R. M., \& March, J. G. (1962). A behavioral theory of the firm. Englewood Cliffs, NJ: Prentice Hall.

Desai, V. (2014). Learning to behave badly: Performance feedback and illegal organizational action. Industrial and Corporate Change, 23, 1327-1355.

Dess, G. G., \& Shaw, J. D. (2001). Voluntary turnover, social capital, and organizational performance. Academy of Management Review, 26, 446-456.

De Vos, A., Buyens, D., \& Schalk, R. (2003). Psychological contract development during organizational socialization: Adaptation to reality and the role of reciprocity. Journal of Organizational Behavior, 24, 537-559.

Dobbie, W., \& Fryer, R. G. (2013). Getting beneath the veil of effective schools: Evidence from New York City. American Economic Journal: Applied Economics, 5, 28-60.

Feng, L., \& Sass, T. R. (2017). Teacher quality and teacher mobility. Education Finance and Policy, 12, 396-418.

Finkel, S. (1995). Causal analysis with panel data. Thousand Oaks, CA: SAGE Publications.

Flink, C. M. (2019). Predicting budgetary change: The effect of performance gaps. Journal of Public Administration Research and Theory, 29, 227-237.

Glebbeek, A. C., \& Bax, E. H. (2004). Is high employee turnover really harmful? An empirical test using company records. Academy of Management Journal, 47, 277-286.

Glymour, M. M., Weuve, J., Berkman, L. F., Kawachi, I., \& Robins, J. M. (2005). When is baseline adjustment useful in analyses of change? An example with education and cognitive change. American Journal of Epidemiology, 162, 267-278.

Goldhaber, D., Gross, B., \& Player, D. (2011). Teacher career paths, teacher quality, and persistence in the classroom: Are public schools keeping their best? Journal of Policy Analysis and Management, 30, 57-87.

Goldring, R., Taie, S., \& Riddles, M. (2014). Teacher attrition and mobility: Results from the 2012-13 Teacher Follow-up Survey (NCES 2014-077). US Department of Education. Washington, DC: National Center for Education Statistics. Retrieved from: http://nces.ed.gov/pubsearch. 
Greve, H. R. (2003). Organizational learning from performance feedback: A behavioral perspective on innovation and change. Cambridge: Cambridge University Press.

Grissom, J. A., Viano, S. L., \& Selin, J. L. (2016). Understanding employee turnover in the public sector: Insights from research on teacher mobility. Public Administration Review, 76, 241-251.

Hale, D., Ployhart, R. E., \& Shepherd, W. (2016). A two-phase longitudinal model of a turnover event: Disruption, recovery rates, and moderators of collective performance. Academy of Management Journal, 59, 906-929.

Hancock, J. I., Allen, D. G., Bosco, F. A., McDaniel, K. R., \& Pierce, C. A. (2013). Meta-analytic review of employee turnover as a predictor of firm performance. Journal of Management, 39, 573-603.

Hanushek, E. A., Kain, J. F., O'Brien, D. M., \& Rivkin, S. G. (2005). The market for teacher quality. Cambridge, MA: National Bureau of Economic Research.

Holm, J. M. (2017). Double standards? How historical and political aspiration levels guide managerial performance information use. Public Administration, 95, 1026-1040.

Holtom, B. C., Mitchell, T. R., Lee, T. W., \& Eberly, M. B. (2008). Turnover and retention research: A glance at the past, a closer review of the present, and a venture into the future. Academy of Management Annals, 2, 231-274.

Hong, S. (2019). A behavioral model of public organizations: Bounded rationality, performance feedback, and negativity bias. Journal of Public Administration Research and Theory, 29, 1-17.

Hu, L., \& Bentler, P. M. (1999). Cutoff criteria for fit indexes in covariance structure analysis: Conventional criteria versus new alternatives. Structural Equation Modeling: A Multidisciplinary Journal, 6, 1-55.

Hvidman, U., \& Andersen, S. C. (2014). Impact of performance management in public and private organizations. Journal of Public Administration Research and Theory, 24, 35-58.

Iyer, D., \& Miller, K. (2008). Performance feedback, slack, and the timing of acquisitions. Academy of Management Journal, 51, 808-822.

Jepsen, C. (2005). Teacher characteristics and student achievement: Evidence from teacher surveys. Journal of Urban Economics, 57, 302-319.

Koys, D. J. (2001). The effects of employee satisfaction, organizational citizenship behavior, and turnover on organizational effectiveness: A unit-level, longitudinal study. Personnel Psychology, 54, 101-114.

Leana, C. R., \& Buren, H. J. V. (1999). Organizational social capital and employment practices. Academy of Management Review, 24, 538-555.

Lee, S. (2018). Employee turnover and organizational performance in US federal agencies. American Review of Public Administration, 48, 522-534.

Loeb, S., Miller, L. C., \& Wyckoff, J. (2015). Performance screens for school improvement: The case of teacher tenure reform in New York City. Educational Researcher, 44, 199-212.

Louis, M. R. (1980). Surprise and sense making: What newcomers experience in entering unfamiliar organizational settings. Administrative Science Quarterly, 25, 226-251.

Love, E. G., \& Nohria, N. (2005). Reducing slack: The performance consequences of downsizing by large industrial firms, 1977-93. Strategic Management Journal, 26, 1087-1108.

Ma, L. (2016). Performance feedback, government goal-setting and aspiration level adaptation: Evidence from Chinese provinces. Public Administration, 94, 452-471.

March, J. G., \& Sutton, R. I. (1997). Crossroads-Organizational performance as a dependent variable. Organization Science, 8, 698-706.

Meier, K. J., Favero, N., \& Zhu, L. (2015). Performance gaps and managerial decisions: A Bayesian decision theory of managerial action. Journal of Public Administration Research and Theory, 25, 1221-1246.

Meier, K. J., \& Hicklin, A. (2008). Employee turnover and organizational performance: Testing a hypothesis from classical public administration. Journal of Public Administration Research and Theory, 18, 573-590.

Meier, K. J., \& O'Toole Jr, L. J. (2002). Public management and organizational performance: The effect of managerial quality. Journal of Policy Analysis and Management: The Journal of the Association for Public Policy Analysis and Management, 21, 629-643.

Moolenaar, N. M., Sleegers, P., \& Daly, A. (2012). Teaming up: Linking collaboration networks, collective efficacy, and student achievement. Teaching and Teacher Education, 28, 251-262.

Moon, K.-K. (2017). Voluntary turnover rates and organizational performance in the US federal government: The moderating role of high-commitment human resource practices. Public Management Review, 19, 1480-1499.

Morrison, E. W. (1993). Longitudinal study of the effects of information seeking on newcomer socialization. Journal of Applied Psychology, 78, 173-183.

Morrow, P., \& McElroy, J. (2007). Efficiency as a mediator in turnover-organizational performance relations. Human Relations, 60, 827-849.

New York City Department of Education (2016). DOE overview. Retrieved from: http://schools.nyc.gov/AboutUs/funding/ overview/default.htm 
Nicholson-Crotty, S., Nicholson-Crotty, J., \& Fernandez, S. (2017). Performance and management in the public sector: Testing a model of relative risk aversion. Public Administration Review, 77, 603-614.

Nielsen, P. A. (2014). Learning from performance feedback: Performance information, aspiration levels, and managerial priorities. Public Administration, 92, 142-160.

No Child Left Behind Act of 2001, P.L. 107-110, 20 U.S.C. $\$ 6319$ (2002).

Park, T.-Y., \& Shaw, J. D. (2013). Turnover rates and organizational performance: A meta-analysis. Journal of Applied Psychology, 98, 268-309.

Rivkin, S. G., Hanushek, E. A., \& Kain, J. F. (2005). Teachers, schools, and academic achievement. Econometrica, 73, 417-458.

Robinson, S. L., \& Rousseau, D. M. (1994). Violating the psychological contract: Not the exception but the norm. Journal of Organizational Behavior, 15, 245-259.

Ronfeldt, M., Loeb, S., \& Wyckoff, J. (2013). How teacher turnover harms student achievement. American Educational Research Journal, 50, 4-36.

Rumberger, R. W., \& Palardy, G. J. (2005). Test scores, dropout rates, and transfer rates as alternative indicators of high school performance. American Educational Research Journal, 42, 3-42.

Salge, T. O. (2011). A behavioral model of innovative search: Evidence from public hospital services. Journal of Public Administration Research and Theory, 21, 181-210.

Schermelleh-Engel, K., Moosbrugger, H., \& Müller, H. (2003). Evaluating the fit of structural equation models: Tests of significance and descriptive goodness-of-fit measures. Methods of Psychological Research Online, 8, 52.

Sharfman, M. P., Wolf, G., Chase, R. B., \& Tansik, D. A. (1988). Antecedents of organizational slack. Academy of Management Review, 13, 601-614.

Shaw, J. D., Gupta, N., \& Delery, J. E. (2005). Alternative conceptualizations of the relationship between voluntary turnover and organizational performance. Academy of Management Journal, 48, 50-68.

Siebert, W. S., \& Zubanov, N. (2009). Searching for the optimal level of employee turnover: A study of a large UK retail organization. Academy of Management Journal, 52, 294-313.

Strober, M. H. (1990). Human capital theory: Implications for HR managers. Industrial Relations, 29, 214-239.

Tan, J., \& Peng, M. W. (2003). Organizational slack and firm performance during economic transitions: Two studies from an emerging economy. Strategic Management Journal, 24, 1249-1263.

Ton, Z., \& Huckman, R. S. (2008). Managing the impact of employee turnover on performance: The role of process conformance. Organization Science, 19, 56-68.

Turnley, W. H., \& Feldman, D. C. (1999). The impact of psychological contract violations on exit, voice, loyalty, and neglect. Human Relations, 52, 895-922.

Zambrano-Gutiérrez, J. C., Rutherford, A., \& Nicholson-Crotty, S. (2017). Types of coproduction and differential effects on organizational performance: Evidence from the New York City school system. Public Administration, 95, 776-790.

Zhao, H., Wayne, S. J., Glibkowski, B. C., \& Bravo, J. (2007). The impact of psychological contract breach on work-related outcomes: A meta-analysis. Personnel Psychology, 60, 647-680.

\section{SUPPORTING INFORMATION}

Additional supporting information may be found online in the Supporting Information section at the end of this article.

How to cite this article: Wang W, Sun R. Does organizational performance affect employee turnover? A reexamination of the turnover-performance relationship. Public Admin. 2020;98:210-225. https://doi.org/10. 1111/padm.12648 